\title{
Propagation of CMORPH rainfall errors to REW streamflow simulation mismatch in the upper Zambezi Basin
}

\author{
W. Gumindoga ${ }^{\text {a,b, }}{ }^{*}$, T.H.M. Rientjes ${ }^{a}$, A.T. Haile ${ }^{c}$, P. Reggiani ${ }^{d}$, H. Makurira $^{b}$ \\ ${ }^{a}$ Faculty ITC, University of Twente, The Netherlands \\ ${ }^{\mathrm{b}}$ University of Zimbabwe, Department of Construction and Civil Engineering, Zimbabwe \\ ${ }^{\mathrm{c}}$ International Water Management Institute (IWMI), Ethiopia \\ ${ }^{\mathrm{d}}$ Department of Civil Engineering, University of Siegen, Germany
}

\section{A R T I C L E I N F O}

\section{Keywords:}

Bias correction

Error

Model calibration

Objective functions

Water balance

Zambezi basin

\begin{abstract}
A B S T R A C T
Study region: This research is carried out in the Kabompo Basin, a headwater catchment of the Zambezi Basin which has an area of $67,261 \mathrm{~km}^{2}$. Kabompo River originates in North-Western Province of Zambia between the Zambezi and Congo River Basins.

Study focus: This study focuses on error propagation of the National Oceanic and Atmospheric Administration (NOAA) Climate Prediction Center-MORPHing (CMORPH) rainfall product on simulated streamflow. Assessments are based on automated multi-objective calibration of the Representative Elementary Watershed (REW) model (2006-2012). Parameters of the model were optimized using the $\varepsilon$-NSGAII algorithm. Assessments on error propagation targeted streamflow modelling for hydrograph shape and volume, specific hydrograph characteristics, and water balance composition.

New hydrological insights for the region: By use of multiple objective functions, this study shows that uncorrected CMORPH results in substantial augmentation of rainfall error to streamflow simulation mismatch whereas bias corrected estimates result in attenuation of error. Analysis for water balance composition has great potential to improve application of satellite precipitation products in water management and decision making in the Zambezi basin. This study advises optimization of model parameters for each respective rainfall input data source so to identify outcomes and effects of respective rainfall data sources on the simulated water balance composition and closure.
\end{abstract}

\section{Introduction}

Propagation effects of rainfall errors in streamflow simulation commonly are assessed by use of in situ-observed rainfall (Fallah et al., 2020; Shin and Kim, 2019). This also is the case for the vastly ungauged Zambezi Basin in southern Africa (Winsemius et al., 2006) which supports livelihoods of over 40 million inhabitants (Hughes and Farinosi, 2020). A constraint to streamflow simulation and hydrological assessments of the basin's water balance is the low number of rain gauges that hinder quantitative assessments. To overcome the constraints by limited rain gauge data, satellite rainfall estimates (SREs) can be considered to supplement, or to replace rain gauge data. Satellite rainfall products provide areal coverages and allow construction of time series since observations are consistently repeated over time.

\footnotetext{
* Corresponding author at: Faculty ITC, University of Twente, The Netherlands.

E-mail addresses: w.gumindoga@utwente.nl,wgumindoga@gmail.com (W. Gumindoga).
} 
Over the past decade, a large number of studies have reported on SRE's. A wider consensus has developed that SREs are affected by observation error. Various studies report on bias error (i.e. systematic error) propagation of SREs that affect specific characteristics of simulated hydrographs such as peak flows (Chen et al., 2020), low and high flows (Dang et al., 2017), as well as the water balance as shown in catchment modelling (Alemu et al., 2020). A study by Jiang et al. (2012) in China highlights SRE bias error propagation by use of the semi-distributed Xinanjiang model and show that relatively small bias-corrected rainfall errors do not distinctly affect model behaviour. Mei et al. (2016) showed that larger bias errors propagated to cause significant streamflow mismatch when the Integrated Catchment Hydrological Model (ICHYMOD) was applied in Italys's Upper Adige River Basin. Pan et al. (2010) showed that the Climate Prediction Center-MORPHing (CMORPH) (Joyce et al., 2004) satellite rainfall errors cause mismatches in simulated streamflow volume using the Variable Infiltration Capacity (VIC) model. Maggioni et al. (2013) used a stochastic ensemble-based satellite rainfall error model (SREM2D) in the Tar-Pamlico Basin and showed that CMORPH rainfall bias errors are significantly augmented to cause streamflow mismatch in large basin sizes. Artan et al. (2007) showed that in the Mekong River's Nam Ou and Se Done Basins, a slight bias in CMORPH rainfall augmented into simulated streamflow mismatch using the Geospatial Stream Flow Model (GeoSFM).

In hydrological modelling, evaluation of SRE rainfall error propagation to streamflow mismatch and to water balance closure are topics of ongoing interest. Propagation of rainfall error to streamflow error by hydrological modelling commonly is evaluated by analysing mismatches between observed streamflow and simulated counterparts subject to respective rainfall input data sources. For that purpose, objective functions may be combined and optimized by use of automated single or multi-objective model calibration algorithms (see De Vos and Rientjes, 2007). Yapo et al. (1998) identifies a set of optimal solutions (model parameter sets) based on a trade-off between different objective functions. De Vos and Rientjes (2007) showed that not all differences between simulated and observed hydrograph characteristics (e.g., peak flows or low flows) can be expressed adequately by a single objective function and optimized model parameter set. Rientjes et al. (2013), Monteil et al. (2020) and Shahed Behrouz et al. (2020) show that multi-objective calibration allows the simultaneous evaluation of multiple outputs from the model. These applications have been on knowledge-driven hydrological model approaches and thus, it is likely that aspects of satellite rainfall error propagation can be assessed from such a calibration approach. In this study, multi-objective strategies are tested for SRE error propagation, to cause mismatch in streamflow hydrograph shape and volume, specific hydrograph characteristics and composition of simulated model-water balance. Effects on

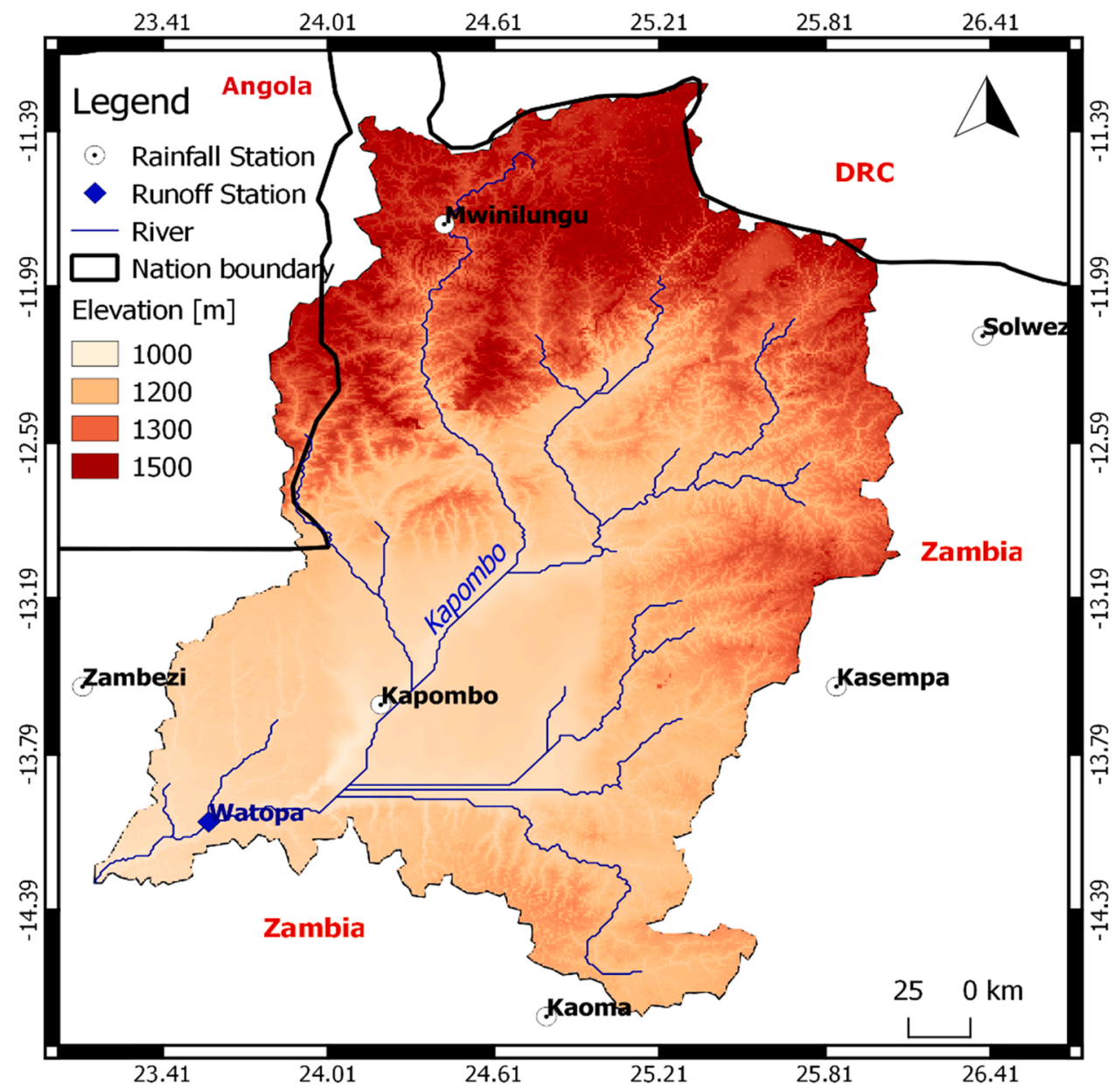

Fig. 1. The Kabompo Basin showing elevation, rainfall, streamflow gauging stations and country boundaries. 
parameter optimization for rainfall input sources is shown as well.

In the Kabompo Basin a number of spatially distributed rainfall-runoff model approaches have been used that relied on use of rain gauge data and SRE's. Omondi (2017) applied the Topographic driven model (TOPMODEL) to assess effectiveness of satellite rainfall estimates for water balance assessment. Ndhlovu and Woyessa (2020) used the Soil and Water Assessment Tool (SWAT) model to determine the impact of climate change on the hydrology of the Kabompo Basin. Matos (2014) successfully used the SWAT model with SREs on a daily time step to forecast flows for the Zambezi River Basin. In the above studies, no attempts were made to assess effects of SRE errors on streamflow mismatch (Ndhlovu and Woyessa, 2020) although there are also ample scientific studies that SRE are affected by systematic errors (Gumindoga et al., 2019c). This study seeks improved understanding of propagation effects of SRE rainfall errors where the state-of-the-art Representative Elementary Watershed modelling approach (Reggiani and Majid Hassanizadeh, 2016) is selected and applied at the Kabompo headwater catchment of the Zambezi River. This study demonstrates how systematic errors (i.e. bias errors) in CMORPH SREs affect simulated streamflow outcomes of a physically based rainfall-runoff model. The study also shows how errors affect actual evapotranspiration $\left(\mathrm{ET}_{\mathrm{a}}\right)$ with emphasis on closure of the water balance. The findings are expected to provide new insights on the hydrologic implications of satellite rainfall error and serves applications in the Zambezi Basin.

\section{Methodology}

\subsection{Description of study area}

The Kabompo River originates in North-Western Province of Zambia between the Zambezi and Congo River basins. The river is approximately $440 \mathrm{~km}$ long. The streamflow gauging station for Kabompo River is located at Watopa Pontoon which is near the basin outlet and has an upstream catchment area of $67261 \mathrm{~km}^{2}$ (Fig. 1).

The predominant soil types are ferralsols, that are deep, strongly leached clayey to loamy soils, covering almost $70 \%$ of the study area. Arenosols that are sandy soils featuring very weak or no significant soil profile development exist and are dispersed in slightly divided plateau zones which shelter the southern and western part of the basin (Gumindoga et al., 2019a). Landcover entails about $60 \%$ closed broadleaved deciduous forest, $22 \%$ open broadleaved deciduous forest and the remainder closed to open shrublands. Kabompo Basin has a sub-tropical climate consisting of a wet season (October - April) and a dry season (May-September). Rainfall is affected by the movement of the Inter-Tropical Convergence Zone (ITCZ). The mean annual precipitation ranges from $900 \mathrm{~mm} / \mathrm{yr}$ in the southern part to $1500 \mathrm{~mm} / \mathrm{yr}$ in the northern part of the basin. Actual evapotranspiration is around $785 \mathrm{~mm} / \mathrm{yr}$ (Omondi, 2017).

\subsection{In situ-observed meteorological and streamflow data}

Daily meteorological data of six stations for the period 1998-2012 were obtained from the Meteorological Department of Zambia and from the University of Zambia. This period was selected because of completeness of rainfall time series. It is also common to find floods and drought within one hydro-meteorological season. The stations are Kabompo, Kaoma, Kasempa, Mwinilunga, Solwezi and Zambezi (Fig. 1). Although the network of the rain gauges is sparse with two stations inside the basin and four stations with average distance of $35 \mathrm{~km}$ outside of the catchment boundary, the network may serve the objectives of this study as stations are well distributed across the study area, and since screening of rainfall data indicated that observation time series are complete and of good quality. Meteorological observations (maximum and minimum temperature, rainfall, relative humidity, wind speed and sunshine) were used to estimate daily potential evapotranspiration (PET) using the Penman-Montheith method (Allen et al., 1998) which were then used as input to a hydrological model.

For the same period, daily streamflow data were obtained for Watopa gauging station from the Department of Water Affairs and Water Resources Management Authority of Zambia. After screening, Watopa station has an average long term flow of $216 \mathrm{~m}^{3} / \mathrm{s}$ (i.e. $1.9 \times 10^{7} \mathrm{~m}^{3} /$ year) with highest flows (up to $1570 \mathrm{~m}^{3} / \mathrm{s}$ ) observed in March and lowest flows (down to $36 \mathrm{~m}^{3} / \mathrm{s}$ ) observed in September.

\subsection{Bias correction of CMORPH based rainfall}

CMORPH rainfall (half hourly estimates) is a gridded precipitation product $(8 \mathrm{~km} \times 8 \mathrm{~km})$ that combines high temporal resolution of Infrared with the high retrieval accuracy of passive Microwave satellite imagery. The product, obtained for the period 1998-2012, has successful applications in the Zambezi Basin (Gumindoga et al., 2019a,b) as well as other African basins (Koriche \& Rientjes 2016; Haile et al., 2013) hence the choice for its use in this study. A detailed description of the product is found in Joyce et al. (2004). CMORPH satellite rainfall images were downloaded from the NOAA Repository: (ftp://ftp.cpc.ncep.noaa.gov/prep/CMORPH_V1.0/CRT/8 $\mathrm{km} 0.30 \mathrm{~m} /$ ), and aggregated to daily totals via the GeoNETCAST ISOD toolbox of ILWIS GIS software (http://52north.org/downloads/).

Bias in CMORPH satellite rainfall estimate is corrected using data from six rain gauges and a space and time varying bias correction approach that was successfully applied for the Zambezi Basin (Gumindoga et al., 2019a, 2019b) and the Upper Blue Nile Basin (Bhatti et al., 2016). Bias correction was performed from 1998 to 2012 that matches the period for error propagation assessment. The bias correction factor adopted from Bhatti et al. (2016) and Habib et al. (2014) is calculated from a 7-day sequential time window that moves forward in the time domain. For all days in the window, an equal bias correction factor is calculated on conditions that, for the window, there is a minimum of five rainy days and a rainfall minimum accumulation depth of $5 \mathrm{~mm}$. When the above conditions are not met, a bias correction factor of 1 applies to all 7 days in the window. In the above approach, bias factors vary in time and space 
since bias factors change value for each station for each 7-day window.

Uncorrected and bias corrected CMORPH rainfall estimates are compared to spatially interpolated gauged rainfall by means of the Inverse Distance approach. By equal projection, pixel-to-pixel comparison at $8 \mathrm{~km} \times 8 \mathrm{~km}$ pixel size and at daily time step is performed for pixels that overlay the study area. To assess the match between gauge observations and uncorrected and corrected $\mathrm{CMORPH} \mathrm{c}$ counterparts, correlation coefficient (CC), root mean squared error (RMSE) and mean absolute error (MAE) are used as statistical indicators.

\section{4. $\varepsilon$-NSGAII for multi-objective model calibration}

In this study, multi-objective calibration is performed for streamflow modelling, for hydrograph shape and volume, combinations of specific hydrograph characteristics, and assessments of water balance composition and closure. The Epsilon Dominance Nondominated Sorting Genetic Algorithm II ( $\varepsilon$-NSGAII) algorithm is applied (Yang et al. 2014) to all cases to optimize model parameters of the rainfall-runoff model (section 2.5). The algorithm is an improved version of the NSGAII algorithm proposed by Deb et al. (2002). The main purpose of the genetic based search algorithm is optimisation of parameter values by fitting simulated streamflow hydrograph variables to observed counterparts. Such can be by single-objective or multi-objective functions. Important settings of the $\varepsilon$-NSGAII that impact effectiveness of the genetic based optimization algorithm are simulated binary crossover (SBX) (Deb and Agrawal, 2005) and polynomial mutation (PM) (Deb and Goyal, 1996). Occurrences of the crossover and mutation operations are complementary inputs which are controlled by the crossover rate (Crate). (Jung et al., 2017) notes that if the Crate is 0.9, the rate of mutation is 0.1 . Function of $\varepsilon$-NSGAII algorithm is based on a number of optimization metrics (i.e. quality measures) that assess cardinality, accuracy, and diversity of solutions as demonstrated in (Mostafaie et al., 2018). The quality measures are the Number of Pareto Solutions (NPS), Generation Distance (GD), Spacing (SP), and Maximum Spread (MS).

\subsection{Representative elementary watershed modelling}

In this study, the Representative Elementary Watershed (REW) model (Reggiani et al., 1999; Reggiani and Rientjes, 2005) is selected for streamflow simulation. The catchment scale model is selected since the semi-distributed model domain reads spatially distributed rainfall as input, and since the model, by means of an integrated physically based numerical approach, simulates runoff production by Hortonian and saturation excess overland flow, and subsurface runoff contributions for shallow and deeper ground water. This allows to intercompare model outcomes, including water balance closure, subject to selected rainfall input data sources.

The semi-distributed model domain constitutes a set of interconnected prismatic volumes (i.e., REW's) that are organized around the stream channel network (Fig. 2). To each flow zone in a REW, conservation equations for mass, momentum, energy and entropy are averaged yielding global balance laws. Detailed descriptions on REW flow algorithms are found in Reggiani et al. (1999) and Reggiani and Rientjes (2005), whereas recent applications of the model are found in Reggiani et al. (2014), Reggiani and Hassanizadeh (2016), Elgamal et al. (2017). Reference is made to Gumindoga et al. (2019a) for an application of the REW model to the Kabompo basin. The
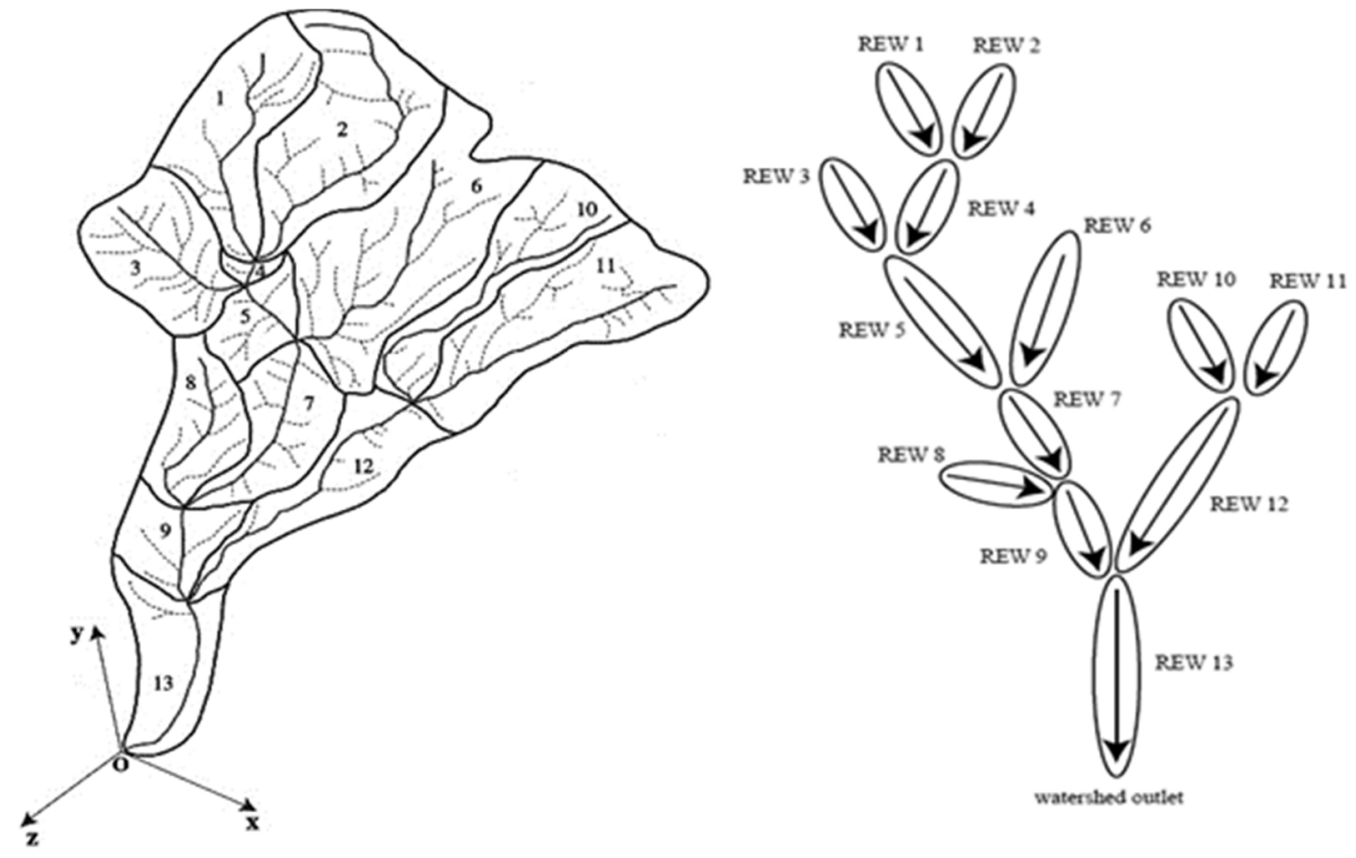

Fig. 2. Organization of REWs around the structure of the network (Reggiani et al., 1998). 
model set-up was adopted in this study as it is well suited for water balance closure assessments in this study.

\subsection{Model calibration and benchmark for rainfall error propagation assessments}

Hydrological modelling requires calibration that serves to optimize the model parameter set given observed rainfall and potential evapotranspiration that force the model. For this study a REW model parameter set with sensitive model parameters was optimized by the $\varepsilon$-NSGAII algorithm using interpolated in-situ observed rainfall for the period from Oct 1998 to Sept 2002. The parameter set was validated for the period Oct 2002 to Sept 2006 by also using interpolated in-situ observed rainfall. For further parameter optimization cases in this study the set will be referred to as the original parameter set with best performing values for further optimization subject to selected SRE rainfall input data source, modelling cases and objective functions.

The selection of calibration and validation periods is based on data availability and completeness. Model performance is assessed from the $Y$ objective function (Akhtar et al., 2009; Rientjes et al., 2013) that combines Nash-Sutcliffe efficiency (NSE) (Nash and Sutcliffe, 1970) and relative volume error (RVE) objective functions (Eqs. (1)-(3)). Y becomes 1 when the model estimates perfectly match with observations and becomes 0 when NSE is equal to 0 . Whereas researchers show that interpreting $Y$ values is not straightforward, in modelling practice, models are assumed to perform well for $Y$ values $>0.6$.

$$
Y=\frac{N S E}{1+|R V E|}
$$

Where:

$$
\begin{aligned}
N S E & =\frac{\sum_{n=1}^{N}\left(O_{n}-Q_{n}\right)^{2}}{\sum_{n=1}^{N}\left(O_{n}-\overline{Q_{n}}\right)^{2}} \\
R V E & =\frac{1}{N} \sum_{n=1}^{N} \frac{O_{n}-Q_{n}}{Q_{n}}
\end{aligned}
$$

$\mathrm{O}=$ observed streamflow $\left(\mathrm{m}^{3} / \mathrm{s}\right), \bar{O}=$ mean of observed streamflow $\left(\mathrm{m}^{3} / \mathrm{s}\right)$.

$\mathrm{Q}=$ simulated streamflow $\left(\mathrm{m}^{3} / \mathrm{s}\right), \bar{Q}=$ mean of simulated streamflow $\left(\mathrm{m}^{3} / \mathrm{s}\right)$.

$\mathrm{N}=$ number of time steps, $\mathrm{n}=$ time interval.

The original parameter set served all other modelling cases were the $\varepsilon$-NSGAII algorithm was applied to optimize parameters subject to selected objective functions and rainfall input data sources. Combination of objective functions (Table 1) are selected with an intention to distinguish high flows, low flows, shape of rising and recession limb flow magnitudes (de Vos and Rientjes, 2008a; Tang et al., 2006; Yapo et al., 1998).

Indicators MSE, M4E, RMSE, MSLE and RMAEL vary between 0 and $\infty$ with a perfect fit of zero (Booij and Krol, 2010). RMERV assesses match of high flows (Booij and Krol, 2010) that may vary between $-\infty$ and $\infty$, but perform best when a value of zero is generated. The recession error constant $\left(\mathrm{r}_{\mathrm{k}}\right)$ function, is calculated for each point by differentiating $\left(\frac{d Q}{d t}\right)$ the Dupuit-Boussinesq equation (Blume et al., 2010). The $\mathrm{r}_{\mathrm{k}}$ function has best performance of 1 .

$$
\begin{aligned}
M S E & =\frac{1}{N} \sum_{n=1}^{N}\left(O_{n}-Q_{n}\right)^{2} \\
M 4 E & =\frac{1}{N} \sum_{n=1}^{N}\left(O_{n}-Q_{n}\right)^{4}
\end{aligned}
$$

Table 1

Hydrograph characteristics assessed and corresponding objective functions.

\begin{tabular}{lll}
\hline Hydrograph shape & Objective functions & Reference \\
\hline $\begin{array}{c}\text { Peak flow (annual } \\
\text { peaks) }\end{array}$ & The Mean Fourth-Power Error (M4E), Time to peak (days) & $\begin{array}{l}\text { (de Vos and Rientjes, 2008b; De Vos and Rientjes, } \\
\text { 2007) } \\
\text { (Booij and Krol, 2010; de Vos and Rientjes, 2005; }\end{array}$ \\
$\begin{array}{ll}\text { High flow } \\
\text { Low flow }\end{array}$ & $\begin{array}{l}\text { Mean Squared Logarithmic Error (MSLE), Relative Mean Absolute Error for Low } \\
\text { (Booij and Krol, 2010; De Vos and Rientjes, 2007; }\end{array}$ \\
$\begin{array}{l}\text { Flow Assessments (RMAEL) } \\
\text { Shape of rising limb } \\
\begin{array}{l}\text { Shape of recession } \\
\text { limb }\end{array}\end{array}$ & $\begin{array}{l}\text { Mean Squared Derivative Error (MSDE), Mean Squared Error (MSE) } \\
\text { (de Vos and Rientjes, 2009) } \\
\text { (Blume et al., 2010) }\end{array}$ \\
\hline
\end{tabular}




$$
\begin{aligned}
& \text { MSLE }=\frac{1}{N} \sum_{n=1}^{N}\left(\operatorname{In} O_{n}-\operatorname{In} Q_{n}\right)^{2} \\
& M S D E=\frac{1}{N} \sum_{n=1}^{N}\left(\left(O_{n}-Q_{n-1}\right)-\left(O_{n}-Q_{n-1}\right)\right)^{2} \\
& R M E R V=100 \times \frac{\frac{R V_{S_{n}}\left(y_{1}\right)-R V_{O_{n}}\left(y_{1}\right)}{R V_{O_{n}}\left(y_{1}\right)}+\frac{R V_{S_{n}} \quad\left(y_{2}\right)-R V_{O_{n}}\left(y_{2}\right)}{R V_{O_{n}}\left(y_{2}\right)}}{2} \\
& \text { RMAEL }=\frac{\sum_{i=1}^{N}\left\lfloor\left|O_{n}(i)-Q_{n}(i)\right|\right\rfloor}{\sum_{i=1}^{N} Q_{n}(i)} \text { withO } O_{n}(i) \leq O_{t} \\
& \text { where: } i=\text { time step, } t=\text { threshold, } y_{1}=10, y 2=100 \\
& r_{k}=\frac{d Q}{d t}\left(\frac{1}{Q(t)}\right) \text { where }: Q(t) \quad \text { is discharge at time } t \quad(\mathrm{~m} 3 / \mathrm{s}),
\end{aligned}
$$

\subsection{Assessments of rainfall error propagation}

Assessments on rainfall error propagation involves a number of objectives and parameter optimization approaches for the assessment period 2006-2012 that is outside periods of calibration and validation. To assess effects of CMORPH rainfall error propagation on hydrograph shape and volume through the Y-function, the original parameter set was selected for all three rainfall data sources. As such any difference in stream flow simulation results can be attributed to error propagation by the CMORPH rainfall input data source subject to the original parameter set. For simulation cases that target specific hydrograph characteristics (Table 1) and water balance assessments, the original parameter set is optimized for respective rainfall input sources and selected objective functions. As such, by rerunning the $\varepsilon$-NSGAII algorithm any aspect of error propagation by rainfall input data source is not affected by suboptimal model parameter values.

\section{Streamflow}

Assessments for SRE rainfall sources on streamflow hydrograph shape and volume(Y-function) use the original parameter set. As such, any mismatch in streamflow that results from respective rainfall input data sources is subject to the original parameter set. Similar to error assessments on rainfall input data sources, for assessing mismatches on streamflow also correlation coefficient (CC), root mean squared error (RMSE) and mean absolute error (MAE) are used as statistical indicators. To indicate effects of error propagation for different rainfall input data sources, ratios of statistical indicators for streamflow $\mathrm{Q}_{\mathrm{s}}$ and rainfall $\mathrm{R}$ are calculated by means of $\mathrm{CC}_{\mathrm{Q}} / \mathrm{CC}_{\mathrm{R}}, \mathrm{MAE}_{\mathrm{Qs}} / \mathrm{MAE}_{\mathrm{R}}$, and $\mathrm{RMSE}_{\mathrm{Qs}} / \mathrm{RMSE}_{\mathrm{R}}$. Ratios are selected because they have different implications: $\mathrm{MAE}_{\mathrm{Q}} / \mathrm{MAE}_{\mathrm{R}}<1$ and $\mathrm{RMSE}_{\mathrm{Q}} / \mathrm{RMSE}_{\mathrm{R}}<1$ implies error attenuation whereas $\mathrm{CC}_{\mathrm{Q}} / \mathrm{CC}_{\mathrm{R}}<1$ implies augmentation of error. Whereas past studies (e.g. Hong et al., 2006) employed error propagation procedures where objective function values are interpreted, in this study, the magnitude of the ratios was considered to indicate effects of propagation in a relative manner.

\section{Stream flow characteristics}

Multi-objective assessments for SRE rainfall sources on specific stream flow hydrograph characteristics follow a procedure where for each set of objective functions (Table 2) and for each rainfall data source a best performing parameter set is used following optimization of the original parameter set by rerunning the $\varepsilon$-NSGAII algorithm. Any difference in objective function values that indicate how well the simulated hydrographs characteristics match to observed counter parts can uniquely be attributed to the rainfall input source.

\section{Water balance}

Water balance assessments imply that subject to the rainfall input data source, water balance components will alter with different volumetric values for respective components. The assessment consider the attribution of rainwater in actual evapotranspiration (ETa) and streamflow $\left(\mathrm{Q}_{s}\right)$, and also accounts for rainwater storage in the model. For error propagation analysis, water balance ratios for actual evapotranspiration over rainfall $\left(\mathrm{ET}_{\mathrm{a}} / \mathrm{R}\right)$ (evapotranspiration coefficient) and runoff over rainfall $\left(\mathrm{Q}_{s} / \mathrm{R}\right)\left(\mathrm{runoff}_{\mathrm{c}}\right.$ coefficient) are computed from the REW simulation. Assessments for all three rainfall data sources are based on Y-function after rerunning the $\varepsilon$-NSGAII algorithm for the assessment period. Besides ratios, the optimized parameter values and water balance components are provided as outcome.

\section{Results and discussion}

\subsection{Bench mark for rainfall error propagation}

Results of the REW model calibration (October 1998-September 2002) and validation (October 2002-September 2006) by use of 


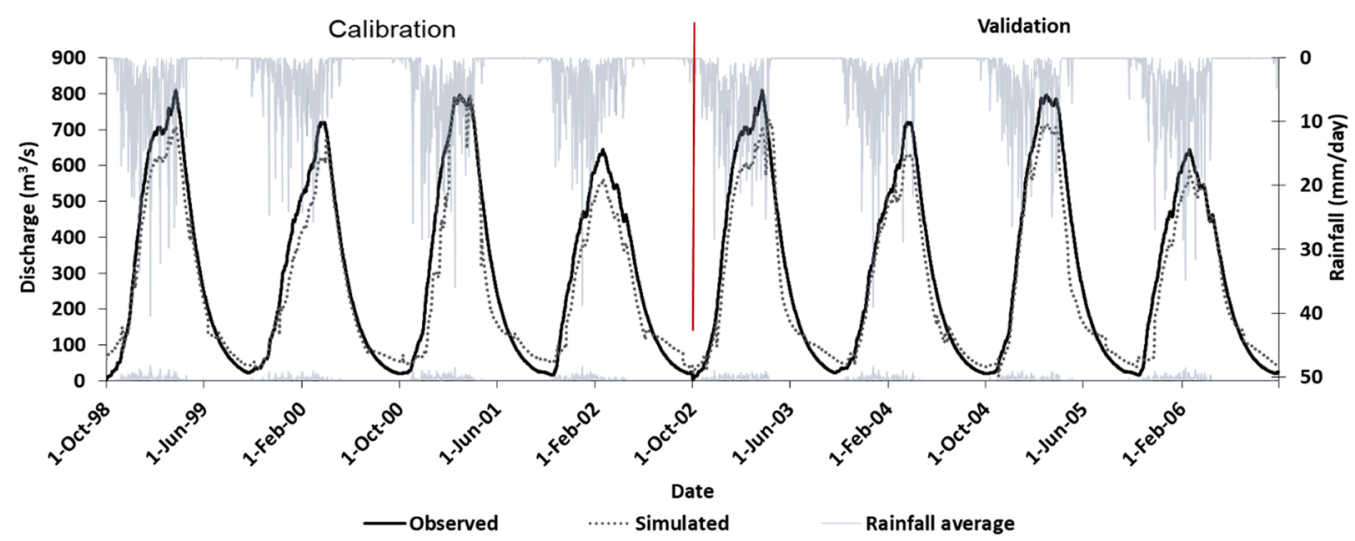

Fig. 3. REW model calibration (October 1998-September 2002) and validation (October 2002-September 2006).

interpolated in-situ observed rainfall are shown in Fig. 3. For both periods model underestimation of highest flows and overestimation of low flows are observed. Hydrograph recession periods are also underestimated for few years. Observed streamflow hydrographs indicate that the Kabompo Basin is a slow responding system as is evident from lack of rapid changes in streamflow over short periods by high rainfall. This is expected considering the large catchment size $\left(67,261 \mathrm{~km}^{2}\right)$. Though the model shows small underestimation of highest peaks and small overestimation of baseflow, the simulated streamflow successfully resembles the observed streamflow pattern during both the calibration $(Y=0.77)$ and validation period $(Y=0.71)$. These objective function values are appropriate to allow for error propagation analysis in this study.

For assessments on SRE error propagation on streamflow mismatch, Fig. 4 shows that for uncorrected CMORPH the ratio $\mathrm{CC}_{\mathrm{Qs}} / \mathrm{CC}_{\mathrm{R}}$ is 2.0 as compared to a lower ratio for corrected $\mathrm{CMORPH}(1.2)$. Any ratio greater $>1$ shows attenuation of error and thus a ratio close to 1 is more desirable. For CC, a ratio $>1$ shows attenuation of error and thus a ratio close to 1 indicates less propogation effect of rainfall. For both $\mathrm{MAE}_{\mathrm{QS}} / \mathrm{MAE}_{\mathrm{R}}$, and $\mathrm{RVE}_{\mathrm{QS}} / \mathrm{RVE}_{\mathrm{R}}$, preferred ratio values are close to 1 , a ratio less than 1 implies error attenuation, whereas a ratio $>1$ shows error augmentation. The ratio $\mathrm{MAE}_{\mathrm{Q}} / \mathrm{MAE}_{\mathrm{R}}$ for uncorrected $\mathrm{CMORPH}$ was 1.3 and indicates error augmentation whereas for bias corrected CMORPH the ratio was 0.2 indicating error attenuation. While there is no substantial difference between uncorrected and corrected $\mathrm{CMORPH}$ for the $\mathrm{RVE}_{\mathrm{QS}} / \mathrm{RVE}_{\mathrm{R}}$ ratio, uncorrected CMORPH however shows error augmentation (1.2) whereas bias corrected CMORPH shows error attenuation (0.9). The error in uncorrected satellite rainfall is shown to amplify in streamflow simulations by the REW model. When corrected CMORPH is introduced, there is attenuation of error. In the context of error propagation, and with reference to the absolute differences between corrected and uncorrected, attenuation is more evident for MAE followed by CC and less substantial for RVE. Overall, the ratios provide insights about the extent of error propagation from rainfall to streamflow mismatch. Substantial error is introduced by uncorrected CMORPH whereas a small error is introduced by corrected CMORPH. The linear bias correction scheme indicates satisfying results in error reduction and is recommended for similar studies.

\subsection{Streamflow for respective rainfall data sources}

Fig. 5 shows the rainfall error propagation simulated hydrograph for the period (2006-2012). Except for baseflow, all hydrograph characteristics show fair match between observed streamflow and the CMORPH simulated streamflow. Time to peak of hydrograph

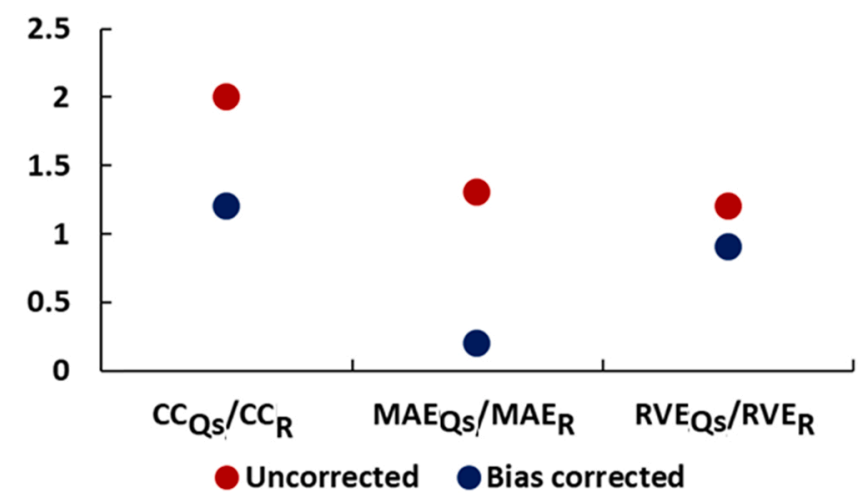

Fig. 4. Ratios $\mathrm{CC}_{\mathrm{Q}} / \mathrm{CC}_{\mathrm{R}}, \mathrm{MAE}_{\mathrm{Q}} / \mathrm{MAE}_{\mathrm{R}}$, and $\mathrm{RMSE}_{\mathrm{QS}} / \mathrm{RMSE}_{\mathrm{R}}$ for uncorrected and bias corrected CMORPH for the 2006-2012 period that coincides with the bias correction period. Note that the calibrated (i.e., original) parameter set was used. 


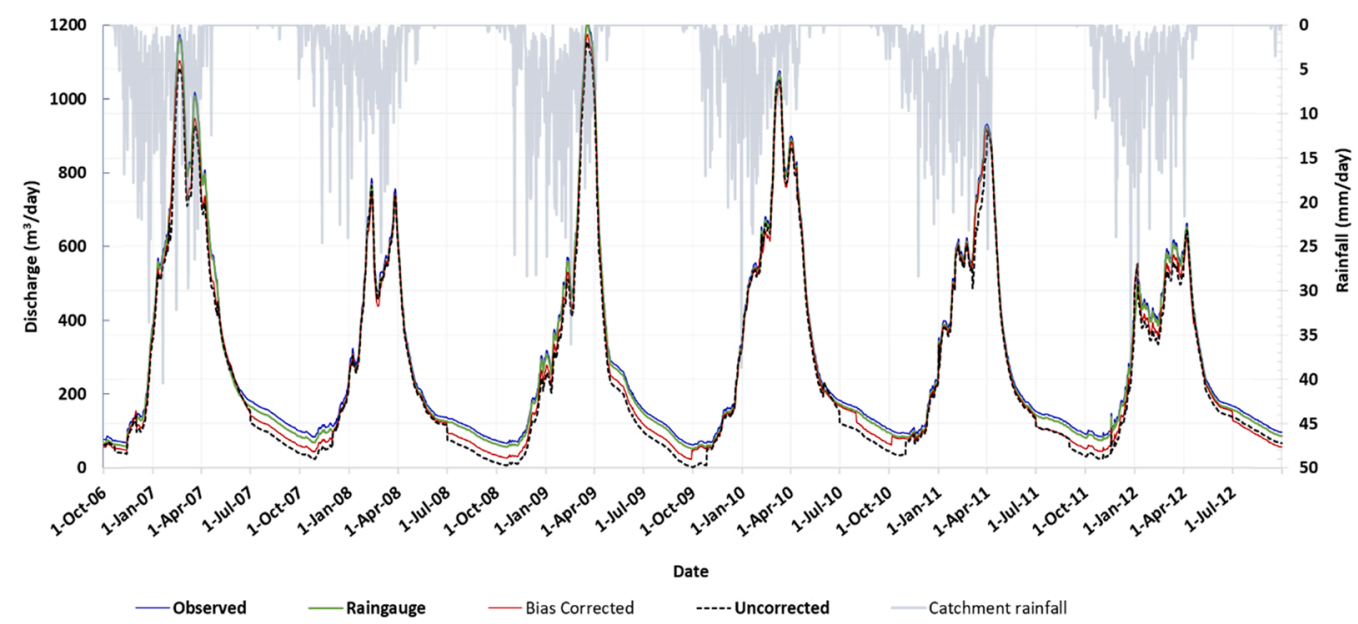

Fig. 5. Simulated hydrographs for respective rainfall data sources after rerunning $\varepsilon$-NSGAII algorithm for Y-function for the period 2006-2012. The catchment rainfall is also shown on secondary axis.

shows that the best hydrograph simulation is indicated for rain gauge-based simulation, that is followed by bias corrected CMORPH and uncorrected CMORPH based streamflow simulation results. There is consistent underestimation of baseflow. There is smooth transition from recession limb to baseflow for the observed hydrograph and model simulations. A drop at the start of baseflow is noted for bias corrected and uncorrected CMORPH based simulations.

\subsection{Streamflow hydrograph characteristics for respective rainfall data sources}

Table 2 shows objective function values used to assess model performance by pairing of objective functions (e.g. the use of NSE and RMERV for high flows). The approach involved further optimization of the original parameter set by rerunning the $\varepsilon$-NSGAII algorithm for respective rainfall sources. This applies to all cases in Table 2.

\section{Peak flow}

Though physical inspection of hydrographs seemingly indicate that all graphs coincide for the highest peaks in each year, $t$, hydrographs for uncorrected CMORPH rainfall are not accurate on the timing of the peak flows. This is based on 'Time to peak' objective function, that only is applied to highest peak flow for each year for the period 2006-2012. Bias corrected rainfall show better matching with observed streamflow peaks as compared to uncorrected CMORPH. For all three rainfall sources, the multi-objective calibration approach in this study improves the M4E by penalising for overestimation of peak flows. There is a trade-off between having good overall fit and having accurate timing to the peak flow (in days), so further research is suggested for a modelling approach so to improve on the trade-offs. de Vos and Rientjes (2005) note that M4E may fail to show effects of a time shift in the runoff series.

\section{High flows}

High flows are defined as flows above the threshold of $500 \mathrm{~m}^{3} / \mathrm{s}$ that coincides with the 75th percentile value range of all observations. Table 2 shows that the NSE values for both corrected and uncorrected CMORPH are in the same order of magnitude for high flows (all in range of 0.64-0.69). The multi-objective parameter optimization by the $\varepsilon$-NSGAII algorithm has preference towards

Table 2

Results of hydrograph characteristic and associated objective functions for multi-objective calibration for rain gauge, uncorrected and bias corrected CMORPH (for the period 2006-2012). Perfect fit is given as NSE $=1, \mathrm{MSE}=0, \mathrm{M} 4 \mathrm{E}=0, \mathrm{MSLE}=0, \mathrm{MSDE}=0, \mathrm{RMSE}=0$, RAMAEL $=0$, $\mathrm{RMERV}=0, \mathrm{r}_{\mathrm{k}}=1$. Bold=best performance noted for uncorrected and corrected CMOPPH.

\begin{tabular}{|c|c|c|c|c|c|c|}
\hline Hydrograph characteristic & Uncorrected & Bias Corrected & Rain gauge & Uncorrected & Bias Corrected & Rain gauge \\
\hline \multirow[t]{2}{*}{ High flow } & NSE & & & RMERV (\%) & & \\
\hline & 0.64 & 0.69 & 0.72 & 4.32 & 1.64 & 1.60 \\
\hline \multirow[t]{2}{*}{ Low flow } & $\operatorname{MSLE}\left(\mathrm{m}^{3} / \mathrm{s}\right)$ & & & RMAEL $\left(\mathrm{m}^{3} /\right.$ & & \\
\hline & $7.1 \mathrm{e}^{-5}$ & $4.9 \mathrm{e}^{-7}$ & $0.5 \mathrm{e}^{-7}$ & 0.62 & 0.34 & 0.20 \\
\hline \multirow[t]{2}{*}{ Shape of rising limb } & $\operatorname{MSE}\left(\mathrm{m}^{3} / \mathrm{s}\right)$ & & & $\operatorname{MSDE}\left(\mathrm{m}^{3} / \mathrm{s}\right)$ & & \\
\hline & 0.0095 & 0.0018 & 0.00097 & $6.3 \mathrm{e}^{-5}$ & $4.5 \mathrm{e}^{-7}$ & $6.8 \mathrm{e}^{-8}$ \\
\hline \multirow[t]{2}{*}{ Peak flow } & M4E $\left(\mathrm{m}^{3} / \mathrm{s}\right)$ & & & Time to peak & & \\
\hline & 0.015 & 0.020 & 0.013 & 6 & 3 & 2 \\
\hline \multirow[t]{2}{*}{ Shape of recession limb } & $r_{k}$ & & & $\operatorname{MSDE}\left(\mathrm{m}^{3} / \mathrm{s}\right)$ & & \\
\hline & 2.3 & 1.2 & 1.1 & $5.5 e^{-6}$ & $4.3 \mathrm{e}^{-7}$ & $4.9 \mathrm{e}^{-8}$ \\
\hline
\end{tabular}


improving hydrograph pattern (higher NSE) and good agreement of high flows (lower RMERV). The combination of NSE and RMERV gives satisfactory results for bias corrected CMORPH rainfall simulations. Uncorrected CMORPH indicated poor results for both NSE and RMERV objective functions.

Low flows

Low flows are flow discharges below the threshold of $95 \mathrm{~m}^{3} / \mathrm{s}$ that coincides with the 25th percentile value range of all observations. Fig. 5 shows that there is match of high flows, rising and falling limbs at the costs of matching low flows. Simulation results possibly are affected by the original parameter set which caused that low flows were over-estimated throughout the entire calibration period (see Fig. 3). Simulation results in Table 2 show relatively poor objective function values for RMAEL and MSLE. Results on magnitude of the low flows indicates satisfying results for bias corrected CMORPH as compared to uncorrected CMORPH. The model simulation with uncorrected CMORPH was successful only for flow values below $25 \mathrm{~m}^{3} / \mathrm{s}$. In Table 2, a large increase in the value of RMAEL is observed for uncorrected CMORPH compared to corrected CMORPH. Furthermore, RMAEL seems to be more appropriate for model calibration than MSLE, although MSLE is used more often (Demirel and Booij, 2009; Madsen, 2000).

\section{Recession limb}

Simulation results in Fig. 5 with uncorrected CMORPH show that the shapes of annual recession curves are not adequately matched as compared to streamflow simulated by in-situ rainfall. This is because of poor rainfall representation by CMORPH in the dry season (see Gumindoga et al., 2019c). Table 2 shows that the simulation with bias corrected CMORPH rainfall results in improved simulation of the recession limb. This is evidenced by $r_{k}$ of 2.3 for uncorrected CMORPH compared to $r_{k}=1.4$ for bias corrected CMORPH. An $r_{k}$ closer to 1 is preferred.

\section{Shape of rising limb}

Fig. 5 shows that yearly rising limbs are well simulated as compared to other hydrograph characteristics except for the recession limb. There is an improved MSE of $0.0018 \mathrm{~m}^{3} / \mathrm{s}$ for bias corrected CMORPH as compared to MSE of $0.0095 \mathrm{~m}^{3} / \mathrm{s}$ for uncorrected CMORPH as shown in Table 2. Similarly, an MSDE value of $6.3 \mathrm{e}^{-5} \mathrm{~m}^{3} / \mathrm{s}$ is achieved for uncorrected CMORPH as compared to an improved value of $4.5 \mathrm{e}^{-7} \mathrm{~m}^{3} / \mathrm{s}$ for bias corrected CMORPH. Overall there is closeness of fit between simulated and observed rising and falling limbs when bias corrected CMORPH rainfall is used.

\subsection{Effect of rainfall data source on the water balance}

The percentage ratios for water balance coefficients $\mathrm{ET}_{\mathrm{a}} / \mathrm{R}$ (evapotranspiration coefficient) and Qs/R (runoff coefficient) are shown in Fig. 6. Ratios are calculated for all three rainfall data input sources for the period 2006-2012 (error assessment period). Highest $\mathrm{ET}_{\mathrm{a}} / \mathrm{R}$ is shown for bias corrected CMORPH (23\%) as compared to uncorrected CMORPH (16\%). Changes in $\mathrm{ET}_{\mathrm{a}} / \mathrm{R}_{\text {for the same error }}$ assessment period are not equal to changes in $\mathrm{Q}_{S} / \mathrm{R}$ in the model indicating that the model responds to actual water storage by rainfall. The results show that the rainfall input source affect the model simulated water balance as the above-mentioned differences are more evident for uncorrected than for corrected CMORPH. Results also show that for uncorrected CMORPH, approximately $9 \%$ of rainfall received is converted to runoff for the period 2006-2012.

Evapotranspiration coefficient shows differences for uncorrected and bias corrected CMORPH based simulations. However, the runoff coefficient does not significantly change when changing the rainfall input data source. Omondi (2017) noted that the low runoff coefficient also implies that most of rainwater in the catchment infiltrates into the soils causing delayed peak runoff (Table 2).

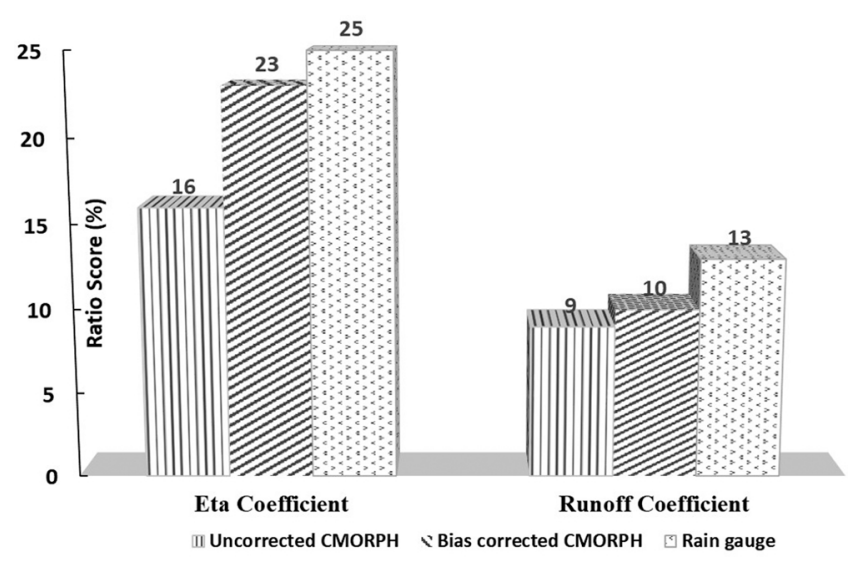

Fig. 6. Percentage ratio scores for water balance coefficients (ETa and Runoff) for the period 2006-2012 for respective rainfall data sources. 
Table 3

Water balance components and closure (2006-2012), and optimized parameter values. Bold= best performance for analysis with satellite rainfall.

\begin{tabular}{lllll}
\hline Parameter & $\begin{array}{l}\text { Water balance component }(\mathrm{mm}) \text { and } \\
\text { Objective function }\end{array}$ & $\begin{array}{l}\text { Rain gauge } \\
\text { Simulation }\end{array}$ & $\begin{array}{l}\text { Uncorrected CMORPH } \\
\text { Simulation }\end{array}$ & $\begin{array}{l}\text { Bias corrected CMORPH } \\
\text { Simulation }\end{array}$ \\
\hline Soil Porosity & & 0.50 & $\mathbf{0 . 5 4}$ & 0.55 \\
Saturated Hydraulic & & 0.006 & 0.0005 & $\mathbf{0 . 0 0 5 8}$ \\
$\quad$ Conductivity $\left[\mathrm{m}^{3} / \mathrm{s}\right]$ & & & & $\mathbf{0 . 5 5}$ \\
Water Content at Saturation & & 0.6 & 0.50 & $\mathbf{3 6 3 5}$ \\
& Rainfall & 3621 & $\mathbf{2 8 2 7}$ \\
& $\mathrm{ET}_{\mathrm{a}}$ & 2850 & $\mathbf{7 1 0 . 8}$ \\
& Streamflow & 718.8 & 7500 & $\mathbf{2 . 6 7}$ \\
& Residual/rain (\%) & 1.44 & 15.91 & $\mathbf{0 . 7 2}$ \\
\hline
\end{tabular}

\subsection{Water balance closure and parameter optimization}

Table 3 shows a comparison of water balance components subject to optimized parameter sets for respective rainfall inputs by rerunning the $\varepsilon$-NSGAII algorithm for the original parameter set. The $Y$-function was selected as objective function (Eq. (1)). Water balance closure represents the water balance equation residual term that is expressed as percentage of rainfall. A residual (1.44 \%) is shown for rain gauge based rainfall input compared to $2.67 \%$ for bias corrected satellite rainfall estimates and $15.91 \%$ for uncorrected CMORPH. Improved closure for corrected CMORPH is also indicated by the higher $Y$ objective function after model calibration.

The study also assessed how model parameters are affected by error in the rainfall inputs after bias correction is applied. Each rainfall distribution (in-situ, uncorrected and bias corrected CMORPH) represents its own amount of rain water that serves model forcing. As such, the REW model responds to the amount of water that it receives. Table 3 also shows results of water balance closure analysis and the different water balance terms that result from the model because of the change of rainfall input source. Respective optimized model parameter values are also indicated (Lee et al., 2005; Reggiani and Rientjes, 2005, 2010; Varado et al., 2006). Soil porosity, saturated hydraulic conductivity and water content at saturation have values within the allowable value ranges. Even after bias correction, sensitive parameters that control the volume of the simulated hydrograph show large changes compared to the parameters using rain gauge input. Factors that control groundwater table depth and eventually baseflows, are less affected.

\subsection{Pareto distributions}

Fig. 7a-1 shows Pareto distributions for sensitive parameters (water content at saturation and soil porosity). Optimization of parameter values by running the $\varepsilon$-NSGAII algorithm for respective rainfall input sources resulted in different trade-offs in the $Y$ objective function. Assessments are made for all hydrograph characteristics but results presented only for low flows, high flows and overall shape. For the same forcing data and objective functions (Table 2), a range of optimum model parameter values result that all perform equally well subject to $\varepsilon$-NSGAII parameter optimization.

The curve shape of the output is the actual Pareto front that shows the trade-off between criterion 1 (x-axis) and 2 (y-axis) for example, if value of water content at saturation improves then for soil porosity it deteriorates (and vice-versa), but any combination shows an equal optimal solution. All the Pareto plots (Fig. 7a-1) multi-objective optimization results in fair spread indicating consistent optimization. A shift of the Pareto front toward the origin of the axes indicates, in a relative sense, error attenuation by the selected bias correction scheme. Such an approach provides a useful guidance for model improvement.

Visual inspection (Fig. 7) and analysis of the quality measures of $\varepsilon$-NSGAII algorithm for calibrating the REW model based on the Y function reveal an improved performance for bias corrected CMORPH rainfall input compared to uncorrected CMORPH. The in-situ rainfall input shows much better performance. In rainfall runoff modelling, a greater NPS number indicates that the algorithm is better suited to provide a greater number of Pareto solutions whereas a better optimization algorithm provide lower GD. An algorithm with a smaller SP indicates that the solutions are distributed (nearly) uniformly, making it a good measure to evaluate diversity. Larger maximum spread values (MS) indicate a good performance of the algorithm as demonstrated in Forootan (2018). A hydrograph overall shape can be thought of as representing averaged conditions of all the other hydrograph characteristic. Results on quality-measures as presented for overall hydrograph shape show: the Number of Pareto Solutions (NPS $=50$ for rain gauge, corrected and uncorrected CMORPH), Maximum Spread (MS = 2.9 = rain gauge, $2.3=$ corrected CMORPH, $0.98=$ uncorrected CMORPH), Generational distance $(\mathrm{GD}, 0.11=$ rain gauge, $0.19=$ corrected $\mathrm{CMOPRH}, 0.22=$ uncorrected $\mathrm{CMORPH})$ and Spacing $(\mathrm{SP}, 1.7 \mathrm{E}-16=$ rain gauge, $1.4 \mathrm{E}-15=$ corrected CMOPRH, 6.8E-15 $=$ uncorrected CMORPH).

\section{Conclusions}

This study successfully assessed effects of SRE error propagation on hydrological modelling by the REW rainfall-runoff model. Parameters of the model were optimized using the $\varepsilon$-NSGAII algorithm. Assessments on error propagation targeted streamflow modelling for hydrograph shape and volume, specific hydrograph characteristics, and water balance composition. From this study, 4 conclusions are drawn: 


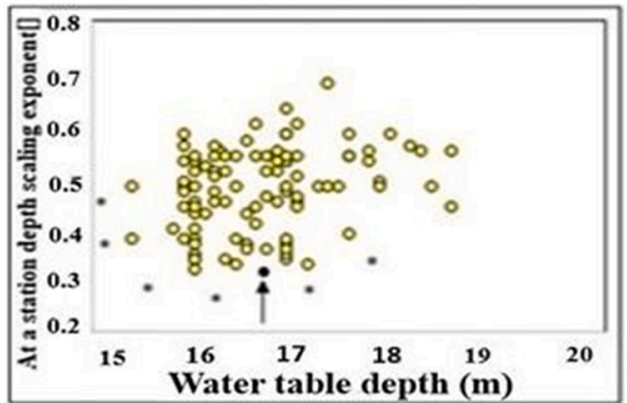

(a) Low flows for UC

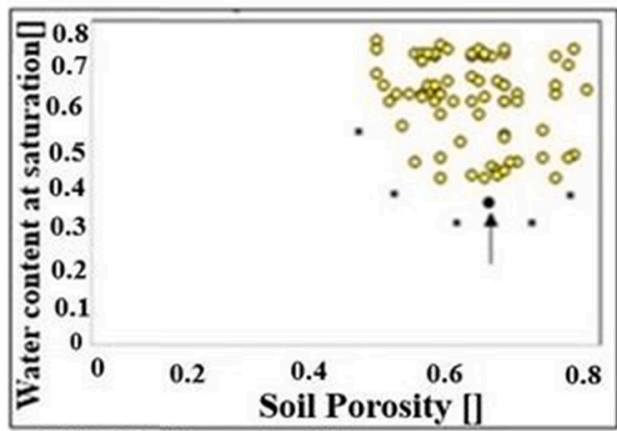

(c) High flows for UC

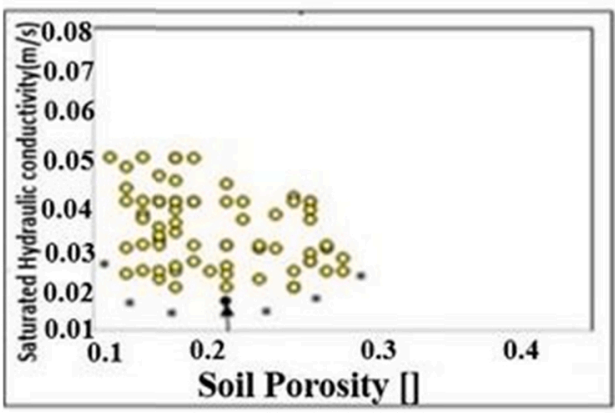

(e) Overal shape for UC

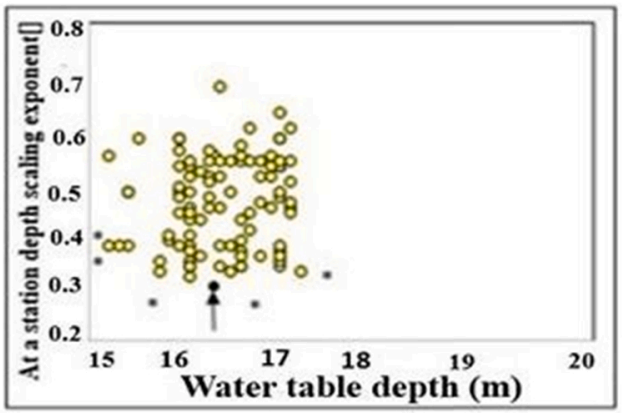

(b) Low flows for BC

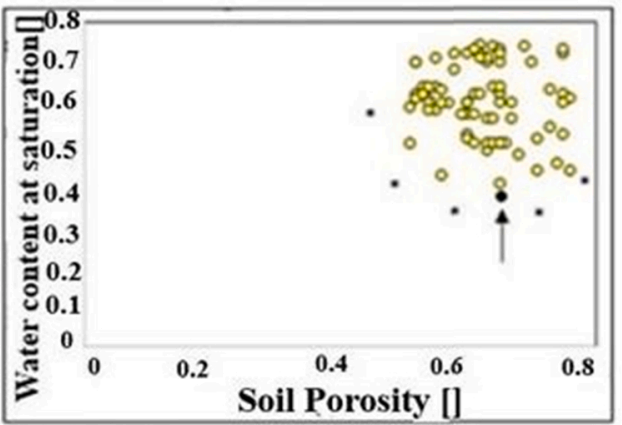

(d) High flows for BC

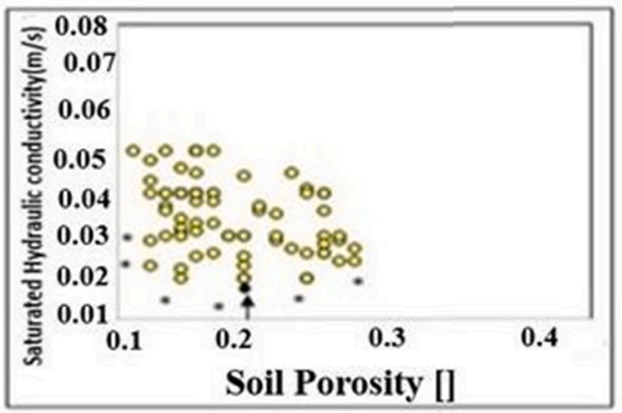

(f) Overal shape for BC

Fig. 7. a-1 Correlation coefficient (CC) values showing trade-off along the Pareto for uncorrected and vias corrected CMORPH. The plots were generated using 100 trials for the $\varepsilon$-NSGAII algorithm.

\section{i. Bench mark for rainfall error propagation}

The REW model successfully simulated runoff in the Kabompo Basin using interpolated in-situ observed rainfall for calibration and validation periods, although some underestimation of highest flows and overestimation of low flows is shown. Sources of uncertainty and error that could contribute to the mismatch are rainfall representation, inaccurate representation of catchment characteristics such as land cover, and stage-discharge relationship.

ii. Streamflow hydrograph mismatch by rainfall error propagation

Ratio indicators that show streamflow error by SRE error indicate that attenuation is more evident for MAE followed by CC and less substantial for RVE functions. Ratios of $\mathrm{MAE}_{\mathrm{Q}} / \mathrm{MAE}_{\mathrm{R}}$ for uncorrected and corrected CMORPH are 1.3 and 0.2; Ratios of $\mathrm{CC}_{\mathrm{Qs}} / \mathrm{CC}_{\mathrm{R}}$ for uncorrected and corrected CMORPH are 2.0 and 1.2; and Ratios of $\mathrm{RVE}_{\mathrm{QS}} / \mathrm{RVE}_{\mathrm{R}}$ for uncorrected and corrected CMORPH are 1.2 and 0.9. This approach showed improved numeric evaluation of CMORPH error propagation as compared to previous studies in the Kabompo Basin, and other catchment basins of the Zambezi River. Results of indicators are affected by use of the original (i.e., calibrated) parameter set that was applied to all three rainfall data sources. Potentially smaller effects of SRE errors may occur when rainfall-runoff simulations are repeated with optimized parameters sets for each respective rainfall input data source.

iii. Mismatch of hydrograph characteristics by rainfall error propagation

Multi-objective parameter optimization enables a more reliable and robust evaluation procedure, and error propagation assessment for specific hydrograph characteristics. Though physical inspection of hydrographs seemingly indicate that all graphs coincide for the highest peaks in each year, the simulations with uncorrected CMORPH rainfall generally are not 
accurate on the hydrograph characteristics. For example, the simulation with bias corrected CMORPH rainfall results in improved simulation of the recession limb $\left(r_{k}\right.$ of 2.3 for uncorrected CMORPH compared to $r_{k}=1.4$ for bias corrected CMORPH). There is also closeness of fit between simulated and observed rising and falling limbs when bias corrected CMORPH rainfall is used. Matching of streamflow hydrograph shows best overall fit in the simulation period for rain gauge-based simulation, that is followed by bias corrected CMORPH and uncorrected CMORPH based streamflow simulation results. Objective function values indicate that bias corrected CMORPH SRE's results in attenuation of CMORPH rainfall bias error.

\section{iv. Effect of error propagation on the water balance closure}

Percentage ratios for water balance coefficients $\mathrm{ET}_{\mathrm{a}} / \mathrm{R}$ (evapotranspiration coefficient) and Qs/R (runoff coefficient) show improved water balance closure for bias corrected CMORPH as compared to uncorrected CMORPH. Findings also show that water balance closure is affected by the multi-objective calibration approach and optimized model parameters for respective rainfall input source. This study shows that error propagation analysis for water balance assessment has great potential to improve application of satellite precipitation products in water management and decision making in the Zambezi basin. This study advises optimization of model parameters for each respective rainfall input data source so to identify outcomes and effects of respective rainfall data sources on the simulated water balance. Optimization of parameter sets by $\varepsilon$-NSGAII results in optimal parameter sets that attributes to findings on the water balance composition and closure in this study as well.

\section{CRediT authorship contribution statement}

W. Gumindoga: Conceptualization, Methodology, Software and modelling, Writing - review \& editing. T.H.M. Rientjes: Conceptualization, Methodology, Supervision, Writing - review \& editing. A.T. Haile: Methodology, Supervision, Writing - review \& editing. P. Reggiani: Software and modelling, Writing - review \& editing. H. Makurira: Supervision, Writing - review \& editing.

\section{Declaration of Competing Interest}

The authors declare no conflict of interests. The funders had no role in the design of the study; in the collection, analyses, or interpretation of data; in the writing of the manuscript, and in the decision to publish the results.

\section{Data Availability}

Data will be provided upon request.

\section{Acknowledgements}

The study was supported by WaterNet through the DANIDA Trans boundary Ph.D. Research in the Zambezi Basin. The research was also supported by University of Twente's ITC Faculty. The authors are grateful to the University of Zimbabwe's Civil Engineering Department for the platform to carry out this research.

\section{References}

Akhtar, M., Ahmad, N., Booij, M.J., 2009. Use of regional climate model simulations as input for hydrological models for the Hindukush-Karakorum-Himalaya region. Hydrol. Earth Syst. Sci. 13, 1075-1089. https://doi.org/10.5194/hess-13-1075-2009.

Alemu, M.L., Worqlul, A.W., Zimale, F.A., Tilahun, S.A., Steenhuis, T.S., 2020. Water balance for a tropical lake in the volcanic highlands: Lake Tana, Ethiopia. Water. https://doi.org/10.3390/w12102737.

Allen, R.G., Pereira, L.S., Raes, D., Smith, M., 1998. Crop evapotranspiration-Guidelines for computing crop water requirements. FAO Irrigation and Drainage Paper 56, FAO, ISBN 92-5-104219-5. Rome, Italy.

Artan, G., Gadain, H., Smith, J., Asante, K., Bandaragoda, C.J., Verdin, J., 2007. Adequacy of satellite derived rainfall data for streamflow modeling. Nat. Haz. 43, 167-185.

Bhatti, H., Rientjes, T., Haile, A., Habib, E., Verhoef, W., 2016. Evaluation of bias correction method for satellite-based rainfall data. Sensors 16 , 884.

Blume, T., Zehe, E., Bronstert, A., Blume, T., Zehe, E., Bronstert, A., 2010. Rainfall - runoff response, event-based runoff coefficients and hydrograph separation 6667. 〈https://doi.org/10.1623/hysj.52.5.843〉.

Booij, M.J., Krol, M.S., 2010. Balance between calibration objectives in a conceptual hydrological model. Hydrol. Sci. J. 55, 1017-1032. https://doi.org/10.1080/ 02626667.2010.505892.

Chen, F., Yuan, H., Sun, R., Yang, C., 2020. Streamflow simulations using error correction ensembles of satellite rainfall products over the Huaihe river basin. J. Hydrol. 589, 125179 https://doi.org/10.1016/j.jhydrol.2020.125179.

Dang, Q.T., Laux, P., Kunstmann, H., 2017. Future high- and low-flow estimations for Central Vietnam: a hydro-meteorological modelling chain approach. Hydrol. Sci. J. 62, 1867-1889. https://doi.org/10.1080/02626667.2017.1353696.

Deb, K., Agrawal, R.B., 2005. Simulated Binary Crossover for Continuous Search Space. Complex Syst 9 (115-148).

Deb, K., Goyal, M., 1996. A Combined Genetic Adaptive Search (GeneAS) for Engineering Design. Computer Science and Informatics 26 (4).

Koriche, S.A., Rientjes, T.H.M., 2016. Application of satellite products and hydrological modelling for flood early warning. Phys. Chem. Earth, Parts A/B/C 93, $12-23$. https://doi.org/10.1016/j.pce.2016.03.007.

Deb, K., Pratap, A., Agarwal, S., Meyarivan, T., 2002. A fast and elitist multiobjective genetic algorithm: NSGA-II. IEEE Trans. Evol. Comput. 6, 182-197. https://doi. org/10.1109/4235.996017.

Demirel, M.C., Booij, M.J., 2009. Identification of an appropriate low flow forecast model for the Meuse River 296-303.

Dhamge, N.R., Atmapoojya, S.L., Kadu, M.S., 2012. Genetic algorithm driven ANN model for runoff estimation. Procedia Technol. 6, 501-508. https://doi.org/ 10.1016/j.protcy.2012.10.060.

Elgamal, A., Reggiani, P., Jonoski, A., 2017. Impact analysis of satellite rainfall products on flow simulations in the Magdalena River Basin, Colombia. J. Hydrol. Reg. Stud. 9, 85-103. https://doi.org/10.1016/j.ejrh.2016.09.001. 
Fallah, A., O, S., Orth, R., 2020. Climate-dependent propagation of precipitation uncertainty into the water cycle. Hydrol. Earth Syst. Sci. 24, 3725-3735. https://doi. org/10.5194/hess-24-3725-2020.

Gumindoga, W., Rientjes, T.H.M., Haile, A.T., Makurira, H., Reggiani, P., 2019a. Performance of bias-correction schemes for CMORPH rainfall estimates in the Zambezi River basin. Hydrol. Earth Syst. Sci. 23, 2915-2938. https://doi.org/10.5194/hess-23-2915-2019.

Gumindoga, W., Rientjes, T.H.M., Haile, A.T., Makurira, H., Reggiani, P., 2019b. Performance evaluation of CMORPH satellite precipitation product in the Zambezi Basin. Int. J. Remote Sens. 40, 1-20. https://doi.org/10.1080/01431161.2019.1602791.

Gumindoga, W., Rientjes, T.H.M., Reggiani, P., Makurira, H., A.T, A, H, 2019c. Hydrologic evaluation of bias corrected CMORPH rainfall estimates at the headwater catchment of the Zambezi River. Phys. Chem. Earth Parts A/B/C. https://doi.org/10.1016/j.pce.2019.11.004.

Habib, E., Haile, A., Sazib, N., Zhang, Y., Rientjes, T., 2014. Effect of bias correction of satellite-rainfall estimates on runoff simulations at the source of the upper Blue Nile. Remote Sens. 6, 6688-6708.

Haile, A.T., Habib, E., Rientjes, T.H.M., 2013. Evaluation of the climate prediction center CPC morphing technique CMORPH rainfall product on hourly time scales over the source of the Blue Nile river. Hydrol. Process. 27, 1829-1839.

Hong, Y., Hsu, K., Moradkhani, H., Sorooshian, S., 2006. Uncertainty quantification of satellite precipitation estimation and Monte Carlo assessment of the error propagation into hydrologic response. Water Resour. Res. 42, W08421 https://doi.org/10.1029/2005WR004398.

Hughes, D.A., Farinosi, F., 2020. Assessing development and climate variability impacts on water resources in the Zambezi River basin. Simulating future scenarios of climate and development. J. Hydrol. Reg. Stud. 32, 100763 https://doi.org/10.1016/j.ejrh.2020.100763.

Jiang, S., Ren, L., Hong, Y., Yong, B., Yang, X., Yuan, F., Ma, M., 2012. Comprehensive evaluation of multi-satellite precipitation products with a dense rain gauge network and optimally merging their simulated hydrological flows using the Bayesian model averaging method. J. Hydrol. 452-453, 213-225. https://doi.org/ 10.1016/j.jhydrol.2012.05.055.

Joyce, R.J., Janowiak, J.E., Arkin, P.A., Xie, P., 2004. CMORPH: a method that produces global precipitation estimates from passive microwave and infrared data at high spatial and temporal resolution. J. Hydromet. 5, 487-503.

Jung, D., Choi, Y.H, Kim, J.H, 2017. Multiobjective Automatic Parameter Calibration of a Hydrological Model. Water 9 (3). https://doi.org/10.3390/w9030187.

Lee, H., Sivapalan, M., Zehe, E., 2005. A Representative Elementary Watershed (REW) approach, a new blueprint for distributed hydrologic modelling at catchment scale. In: Predictions in ungauged basins: International perspectives on state-of-the-art and pathways forward, Proceedings of the Predictions in Ungauged Basins (PUB) workshop, Perth, Australia, 2-5 February 2004.

Madsen, H., 2000. Automatic calibration of a conceptual rainfall-runoff model using multiple objectives. J. Hydrol. 235, 276-288. https://doi.org/10.1016/S00221694(00)00279-1.

Maggioni, V., Vergara, H.J., Anagnostou, E.N., Gourley, J.J., Hong, Y., Stampoulis, D., 2013. Investigating the applicability of error correction ensembles of satellite rainfall products in river flow simulations. J. Hydrometeorol. 14, 1194-1211. https://doi.org/10.1175/JHM-D-12-074.1.

Matos, J.P., 2014. Hydraulic-hydrologic model for the Zambezi River using satellite data and artificial intelligence techniques, Communication (Laboratoire de constructions hydrauliques, Ecole polytechnique fédérale de Lausanne). EPFL - LCH. 〈https://doi.org/10.5075/epfl-lchcomm-60〉.

Mei, Y., Nikolopoulos, E.I., Anagnostou, E.N., Zoccatelli, D., Borga, M., 2016. Error analysis of satellite precipitation-driven modeling of flood events in complex Alpine Terrain. Remote Sens. 8, 293.

Monteil, C., Zaoui, F., Le Moine, N., Hendrickx, F., 2020. Multi-objective calibration by combination of stochastic and gradient-like parameter generation rules - the caRamel algorithm. Hydrol. Earth Syst. Sci. 24, 3189-3209. https://doi.org/10.5194/hess-24-3189-2020.

Mostafaie, A., Forootan, E., Schumacher, N., 2018. Comparing multi-objective optimization techniques to calibrate a conceptual hydrological model using in situ runoff and daily GRACE data. Computational Geosciences 22 (789-814).

Nash, J.E., Sutcliffe, J.V., 1970. River flow forecasting through conceptual models. Part I: a discussion of principles. J. Hydrol. 10, 282-290.

Ndhlovu, G.Z., Woyessa, Y.E., 2020. Modelling impact of climate change on catchment water balance, Kabompo River in Zambezi River Basin. J. Hydrol. Reg. Stud. 27, 100650 https://doi.org/10.1016/j.ejrh.2019.100650.

Omondi, Calisto Kennedy, 2017. Assessment of bias corrected satellite rainfall products for streamflow simulation: A TOPMODEL application in the Kabompo River Basin, Zambia Assessment of bias corrected satellite rainfall products for streamflow simulation: A TOPMODEL application in.

Omondi, C.K., 2017. Assessment of bias corrected satellite rainfall products for streamflow simulation: A TOPMODEL application in the Kabompo River Basin. Water Resour. University of Twente, Enschede, The Netherlands.

Pan, M., Li, H., Wood, E., 2010. Assessing the skill of satellite-based precipitation estimates in hydrologic applications. Water Resour. Res. 46. https://doi.org/ $10.1029 / 2009$ WR008290.

Reggiani, P., Hassanizadeh, S.M., Sivapalan, M., Gray, W.G., 1999. A unifying framework for watershed thermodynamics: constitutive relationships. Adv. Water Resour. 23, 15-39.

Reggiani, P., Majid Hassanizadeh, S., 2016. Megascale thermodynamics in the presence of a conservative field: The watershed case. Adv. Water Resour. 97, 73-86. https://doi.org/10.1016/j.advwatres.2016.09.002.

Reggiani, P., Rientjes, T.H.M., 2005. Flux parameterization in the representative elementary Watershed (REW) approach: application to a natural basin. Water Resour. Res. 41, W04013.

Reggiani, P., Rientjes, T.H.M., 2010. Closing horizontal groundwater fluxes with pipe network analysis: an application of the REW approach to an aquifer. Environ. Model. Softw. 25, 1702-1712. https://doi.org/10.1016/j.envsoft.2010.04.019.

Reggiani, P., Sivapalan, M., Hassanizadeh, S.M., 1998. A unifying framework for watershed thermodynamics: balance equations for mass, momentum, energy and entropy and the second law of thermodynamics. Adv. Water Resour. 22, 367-398.

Reggiani, P., Todini, E., Meißner, D., 2014. A conservative flow routing formulation: Déjà vu and the variable-parameter Muskingum method revisited. J. Hydrol. 519, 1506-1515. https://doi.org/10.1016/j.jhydrol.2014.08.057.

Rientjes, T.H.M., Muthuwatta, L.P., Bos, M.G., Booij, M.J., Bhatti, H.A., 2013. Multi-variable calibration of a semi-distributed hydrological model using streamflow data and satellite-based evapotranspiration. J. Hydrol. 505, 276-290. https://doi.org/10.1016/j.jhydrol.2013.10.006.

Shahed Behrouz, M., Zhu, Z., Matott, L.S., Rabideau, A.J., 2020. A new tool for automatic calibration of the Storm Water Management Model (SWMM). J. Hydrol. 581, 124436 https://doi.org/10.1016/j.jhydrol.2019.124436.

Shin, M.-J., Kim, C.-S., 2019. Analysis of the effect of uncertainty in rainfall-runoff models on simulation results using a simple uncertainty-screening method. Water $11,1361$.

Tang, Y., Reed, P., Wagener, T., 2006. How effective and efficient are multiobjective evolutionary algorithms at hydrologic model calibration? Hydrol. Earth Syst. Sci. 10, 289-307. https://doi.org/10.5194/hess-10-289-2006.

Varado, N., Braud, I., Galle, S., Le Lay, M., Seguis, L., Kamagate, B., Depraetere, C., 2006. Multi-criteria assessment of the Representative Elementary Watershed approach on the Donga catchment (Benin) using a downward approach of model complexity. Hydrol. Earth Syst. Sci. 10, 427-442.

de Vos, N.J., Rientjes, T.H.M., 2008a. Correction of timing errors of artificial neural network rainfall-runoff models. In: Abrahart, R.J., See, L.M., Solomatine, D.P. (Eds.), Practical Hydroinformatics: Computational Intelligence and Technological Developments in Water Applications. Springer Berlin Heidelberg, Berlin, Heidelberg, pp. 101-112 https://doi.org/10.1007/978-3-540-79881-1_8 LB - de Vos2008.

de Vos, N.J., Rientjes, T.H.M., 2008b. Multiobjective training of artificial neural networks for rainfall-runoff modeling. Water Resour. Res. 44 https://doi.org/ $10.1029 / 2007$ WR006734.

de Vos, N.J., Rientjes, T.H.M., 2005. Constraints of artificial neural networks for rainfall-runoff modelling: trade-offs in hydrological state representation and model evaluation. Hydrol. Earth Syst. Sci. 9, 111-126. https://doi.org/10.5194/hess-9-111-2005.

De Vos, N.J., Rientjes, T.H.M., 2007. Multi-objective performance comparison of an artificial neural network and a conceptual rainfall—runoff model. Hydrol. Sci. J. 52, 397-413. https://doi.org/10.1623/hysj.52.3.397. 
Winsemius, H.C., Savenije, H.H.G., Gerrits, A.M.J., Zapreeva, E.A., Klees, R., 2006. Comparison of two model approaches in the Zambezi river basin with regard to model reliability and identifiability. Hydrol. Earth Syst. Sci. 10, 339-352.

Yang, J., Castelli, F., Chen, Y., 2014. Multiobjective sensitivity analysis and optimization of distributed hydrologic model MOBIDIC 4101-4112. 〈https://doi.org/10. 5194/hess-18-4101-2014).

Yapo, P.O., Gupta, H.V., Sorooshian, S., 1998. Multi-objective global optimization for hydrologic models. J. Hydrol. 204, 83-97. https://doi.org/10.1016/S00221694(97)00107-8. 